This is the final peer-reviewed accepted manuscript of:

M. Boselli • M. Gherardi • V. Colombo,

3D modelling of the synthesis of copper nanoparticles by means of a DC transferred arc twin torch plasma system

Journal of Physics D: Applied Physics, Volume 52, Number 44051

The final published version is available online at:

https://doi.org/10.1088/1361-6463/ab3607

Rights / License:

The terms and conditions for the reuse of this version of the manuscript are specified in the publishing policy. For all terms of use and more information see the publisher's website.

This item was downloaded from IRIS Università di Bologna (https://cris.unibo.it/)

When citing, please refer to the published version. 


\title{
3D modelling of the synthesis of copper nanoparticles by means of a DC transferred arc twin torch plasma system
}

\author{
M. Boselli • M. Gherardi • V. Colombo
}

Alma Mater Studiorum-Università di Bologna, Department of Industrial Engineering, Viale del Risorgimento 2, 40136 Bologna, Italy

\begin{abstract}
An atmospheric pressure DC transferred arc twin torch thermal plasma system has been characterized by $3 \mathrm{D}$ simulation in order to assess its potential for the synthesis of $\mathrm{Cu}$ nanoparticles from solid precursors. The numerical model also takes into account the non-negligible effect on process temperature of radiative losses, transport and thermodynamic properties of $\mathrm{Cu}$ vapour. In the frame of design-oriented simulation and optimization of the synthesis process, mean diameter and yield of the synthetized nanoparticles have been investigated for different current levels, gas flow rates, precursor feed rates and nanoparticles model. Results show that evaporation efficiency is considerably high even at precursor feed rates up to $25 \mathrm{~kg} /$ day, while the presence of vortices inside the chambers causes a significative loss of nanoparticles to the reactor walls, with a detrimental effect to the yield.
\end{abstract}

\section{Introduction}

Thermal plasmas [1-3], especially radio-frequency induction thermal plasmas (RF-ITP), are effective tools for continuous nanoparticles synthesis at high throughput. The working principle consists in injecting a solid or liquid precursor inside the plasma region, where it melts (if solid, like in the case of this work) and evaporates due to high temperatures (commonly, $8000 \mathrm{~K}$ at least in all thermal plasma systems). The vaporized material then becomes supersaturated due to the characteristically steep cooling encountered in the fringes of the plasma region and nucleation occurs; these nuclei then grow because of condensation and coagulation. However, as the process is characterized by a large number of variables, 
optimization is a challenging task, that often cannot rely on experimental try and fail approaches, due to high equipment cost and the limited amount of data that can be obtained from experimental diagnostic techniques. For this reason, the investigation of the performance of thermal plasmas processes for nanoparticle synthesis has relied extensively on modelling techniques [4-10].

The performance of the process can be evaluated by the yield and by the fraction of the injected precursor that is effectively evaporated in the plasma (precursor evaporation efficiency). Precursor dimensions and feed rate strongly influence precursor evaporation efficiency: in the region where the material is injected the plasma is affected by a local cooling caused by precursor feed rates, possibly with detrimental effect on the precursor heating (loading effect) [11]. The evaporation efficiency is also limited by the radiative power loss coming from the vapour present in the plasma. Most metal vapours have high emissivity and significantly reduce the precursor evaporation efficiency [12-14].

Quench gas injection is perhaps the optimization parameter most thoroughly investigated, because it impacts strongly on flow fields, temperature distribution and cooling rates in the system [15-18]. The cooling rate that can be generated by the quench gas allows for the synthesis of nanoparticles with a narrow Particle Size Distribution (PSD). Additionally, the type and position of the quenching injection, together with the geometry of the reaction chamber, have been shown to affect the properties and the production rate of the synthetized nanoparticles [11, 19-20]. Quench gas injection operates with several hundreds of standard litres per minute of inert gas, usually Ar.

DC transferred arc twin torch plasma systems torch are devices consisting of two electrodes generating a plasma arc sustained by means of an electric current flowing through the body of the discharge; this plasma arc is typically characterized by a very high temperature (20-30 kK) [21] and operating power usually in the 0.2-2.4 MW range, which could provide at high precursor feed rates an higher evaporation rate compared to RF-ITP systems. Twin torches are intrinsically asymmetrical systems, with cathodic and anodic electrodes having their axes tilted with respect to the vertical; the discharge generated by this particular plasma source configuration is characterized by a complex shape and fluid dynamic behaviour and a 3D description is needed in order to realistically predict it. 3D models have been previously used to study temperature and velocity distribution of such devices with local thermodynamic equilibrium (LTE) assumption [22-25] or even assuming non-LTE [24]. Compared to RF-ITP [1-4,6,8-9], few papers have been published on twin torch plasma systems [22-25], possibly due to the heavy computational load required for 3D plasma modelling, and, in the author's experience, no papers have been published on modelling of nanoparticle synthesis process by twin torch plasma systems.

In this paper we present a static 3D LTE model for the synthesis of $\mathrm{Cu}$ nanoparticles in Ar plasma by evaporation of micrometric solid $\mathrm{Cu}$ precursors in a twin torch plasma system. This work has been performed in the frame of the Horizon 2020 "INdustrial Scale Production of Innovative nanomateRials for printEd Devices" (INSPIRED) project for the scale up of $\mathrm{Cu}$ nanoparticles synthesis to appropriate industrial scale quantities (more than $20 \mathrm{~kg} /$ day of throughput).

This paper can be of some help in evaluating the potentialities of nanoparticle synthesis with a twin torch plasma system, such as process control and efficiencies as well as technical requirements, such as the design of the reaction chamber and quenching gas injection, as well as sizing for gas recycling systems to manage the conspicuous quenching gas consumption. Even if twin torch systems are being 
commercialized on the market also for the purpose of nano-synthesis of materials, a deep understanding of this topic is still neglected in literature; especially when compared to the abundant number of works on RF-ITP nano-synthesis.

\section{Modelling approach}

The nanoparticle synthesis process, including plasma thermo-fluid dynamics, electromagnetic field, precursor injection and evaporation, and nanoparticle formation, transport and growth, is modelled in the ANSYS FLUENT@ environment [26], within a 3D framework. The employed models describe plasma thermo-fluid-dynamics, electromagnetic field, precursor behaviour (injection, trajectories, thermal history and evaporation) and nanoparticle formation, transport and growth.

\subsection{Plasma modelling}

The governing equations and assumptions for plasma thermo-fluid-dynamics calculations are described in [13]. The equations have been properly implemented in a3D environment, moreover, not only the effect of $\mathrm{Cu}$ vapour on radiative losses of the gas mixture, but also on the transport and thermodynamic properties is considered.

Plasma thermodynamic and transport properties for $\mathrm{Ar}$ and $\mathrm{Cu}$ (specifically for $\mathrm{Cu}$, electrical conductivity, density, viscosity and thermal conductivity) in LTE have been computed as in [27]. In calculating the radiative losses, the contributions from both $\mathrm{Ar}$ and $\mathrm{Cu}$ vapour are taken into account, using data from [28]. The volumetric radiative loss was obtained by linear interpolation of the Net Emission Coefficients (NEC) based on the molar fractions of $\mathrm{Ar}$ and $\mathrm{Cu}$ vapour, as suggested by Gleizes et al. [29].

The Lorentz force, $\boldsymbol{F}_{\boldsymbol{L}}$, and Joule dissipation, $P_{J}$, can be expressed as:

$F_{L}=J \times B$

$P_{J}=\boldsymbol{J} \cdot \boldsymbol{E}$

where $\boldsymbol{B}$ and $\boldsymbol{E}$ are the magnetic and electric field respectively and $\boldsymbol{J}$ is the current density.

The electromagnetic field is calculated using Maxwell's equations written explicitly for the vector potential $\boldsymbol{A}$ and scalar potential $V$. The vector and scalar potential equations are solved in the following form:

$\nabla^{2} \boldsymbol{A}-\mu_{0} \sigma \boldsymbol{E}=0$

$\nabla \cdot(\sigma \nabla V)=0$ 
where $\sigma$ is the electrical conductivity; the electric field is related to the gradient of the scalar potential $(\boldsymbol{E}=-\nabla V)$ and the current density has been calculated using the simplified Ohm's law, neglecting the Hall current $\boldsymbol{J}=\sigma \boldsymbol{E}$.

The precursor model adopts the assumptions and equations presented in [30].

\subsection{The nanoparticle synthesis model}

In this paper two different models have been adopted for nanoparticle synthesis: the method of the moments and the nodal model. The method of moments equations have been described in [13], as well as the assumptions for both the models.

In the nodal model a logarithmic scale linear discretization of the PSD function is employed, as proposed by $[6,31]$ :

$v_{p_{n+1}}=\lambda v_{p_{n}} \quad n=0,1, \ldots, n_{\max }$

where $v_{p}$ the particle volume, $\lambda$ is the geometric spacing factor, fixed at 1.6 and $n_{\text {max }}$, the number of nodes, is 42 .

The value of $v_{p_{0}}$, is definded in order to obtain a discretized PSD covering the entire range of particles produced; $v_{p_{0}}$ is considered ten times the volume of the $\mathrm{Cu}$ monomer, $v_{1}$.

Therefore, the discretized aerosol general dynamic equation for the particle distribution $N_{p}$ at node $n$, considering turbulent effects, takes the following form:

$\nabla \cdot\left(\boldsymbol{u} N_{p_{n}}\right)=\nabla \cdot\left(D_{p_{n}}^{\text {tot }} \nabla N_{p_{n}}\right)+\left(\dot{N}_{p_{n}}\right)^{n u c l}+\left(\dot{N}_{p_{n}}\right)^{\text {cond }}+\left(\dot{N}_{p_{n}}\right)^{\text {coag }}$

Where $\boldsymbol{u}$ is the velocity vector, $N_{p_{n}}$ is the particle concentration at node $n, D_{p_{n}}^{\text {tot }}$ the total diffusion coefficient for particles at node $n,\left(\dot{N}_{p_{n}}\right)^{n u c l}$ the nucleation source term, $\left(\dot{N}_{p_{n}}\right)^{\text {cond }}$ the condensation source term and $\left(\dot{N}_{p_{n}}\right)^{\text {coag }}$ the coagulation net production rate. The net production rate at node $n$ by nucleation is defined as:

$$
\left(\dot{N}_{p_{n}}\right)^{n u c l}=I \xi_{n}^{n u c l}
$$

Where $I$ is the nucleation rate, as proposed in [32] and $\xi_{n}^{n u c l}$ is the nucleation size operator, introduced to distribute the nanoparticles generated at volume $v^{*}$ in the proper node:

$\xi_{n}^{n u c l}=\left\{\begin{array}{lc}\frac{v^{*}}{v_{p_{j}}} & \text { if }\left(v_{p_{j-1}}<v^{*}<v_{p_{j}}\right) \\ \frac{v^{*}}{v_{1}} & \text { if }\left(v^{*}<v_{1}\right) \\ 0 & \text { otherwise }\end{array}\right.$

Where $v_{p_{j}}$ is the volume of the particle corresponding to the $j^{\text {th }}$ node.

The condensation source term for the node $n$ is defined as: 
$\left(\dot{N}_{p_{n}}\right)^{\text {cond }}=\sum_{j} \frac{\left(\xi_{j n}^{\text {cond }}-\delta_{j_{n}}\right) N_{p_{j}}}{\Delta t}$

where $\Delta t$ is the condensation time lag, $\delta_{j_{n}}$ the Kroenecker delta and $\xi_{j n}^{c o n d}$ the size splitting operator graphically and defined as:

$\xi_{j n}^{\text {cond }}=\left\{\begin{array}{cc}\frac{v_{p_{n+1}}-\left(v_{p_{j}}+\Delta v_{p_{j}}\right)}{v_{p_{n+1}}-v_{p_{n}}} & \text { if }\left(v_{p_{n}}<v_{p_{j}}+\Delta v_{p_{j}}<v_{p_{n+1}}\right) \\ \frac{\left(v_{p_{j}}+\Delta v_{p_{j}}\right)-v_{p_{n-1}}}{v_{p_{n}}-v_{p_{n-1}}} & \text { if }\left(v_{p_{n-1}}<v_{p_{j}}+\Delta v_{p_{j}}<v_{p_{n}}\right) \\ 0 & \text { otherwise }\end{array}\right.$

Where the volume increment of each particle due to condensation is determined by [33]:

$\frac{d v_{p_{j}}}{d t}=2 \pi d_{p_{j}} D_{v a p}^{L} v_{1}\left(n_{1}-n_{S_{j}}^{\prime}\right)\left(\frac{0.75 \alpha\left(1+K n_{j}\right)}{0.75 \alpha+0.283 \alpha K n_{j}+K n_{j}+K n_{j}^{2}}\right)$

where $n_{1}$ is the vapour concentration, $n_{S_{j}}^{\prime}$ is the vapour concentration at saturation considering the Kelvin effect for the vapour interacting with the $j^{\text {th }}$ node particle and $\alpha$ is the condensation accommodation coefficient, whose value ranges from to 0.013 to 0.38 , according to [34]; here a value of 0.05 is used, as proposed in [17].

The coagulation source term is expressed by Smoluchowski's equation [35], where every time a particle of volume $v_{p_{i}}$ collides with a particle of volume $v_{p_{j}}$, a coagulated particle of volume $v_{p_{i}}+v_{p_{j}}$ is formed:

$\left(\dot{N}_{p_{n}}\right)^{\text {coag }}=\frac{1}{2} \sum_{i} \sum_{j} \xi_{i j n}^{\text {coag }} \beta_{i j} N_{p_{i}} N_{p_{j}}-N_{p_{n}} \sum_{i} \beta_{i n} N_{p_{i}}$

Where subscripts $i$ and $j$ denote the nodes to which the colliding particles belong and $\xi_{i j n}^{\text {coag }}$ is the coagulation size splitting operator and defined as:

$\xi_{i j n}^{\text {coag }}=\left\{\begin{array}{cc}\frac{v_{p_{n+1}}-\left(v_{p_{i}}+v_{p_{j}}\right)}{v_{p_{n+1}}-v_{p_{n}}} & \text { if }\left(v_{p_{n}}<v_{p_{i}}+v_{p_{j}}<v_{p_{n+1}}\right) \\ \frac{\left(v_{p_{i}}+v_{p_{j}}\right)-v_{p_{n-1}}}{v_{p_{n}}-v_{p_{n-1}}} & \text { if }\left(v_{p_{n-1}}<\left(v_{p_{i}}+v_{p_{j}}\right)<v_{p_{n}}\right) \\ 0 & \text { otherwise }\end{array}\right.$

While $\beta_{i j}$ is the collision frequency proposed by [28] to cover wide particle size ranges.

\subsection{Material properties}

The physical properties for $\mathrm{Cu}$ powders are reported in Table 1 and were taken from [36-37]. Microsized $\mathrm{Cu}$ precursor particles are injected through the probe by means of the Ar carrier gas with different feed rates spanning from $0.23 \mathrm{~kg} / \mathrm{h}$ to $4 \mathrm{~kg} / \mathrm{h}$ and were assumed to have a Rosin-Rammler distribution with mean diameter of $7.3 \mu \mathrm{m}$. 
Table 1 Physical properties for $\mathrm{Cu}$ powders

\begin{tabular}{|c|c|c|}
\hline Property & Units & Value \\
\hline$\rho_{p}$ & $\mathrm{~kg} \mathrm{~m}^{-3}$ & 8900 \\
\hline$c_{p}$ & $\mathrm{~J} \mathrm{~kg}^{-1} \mathrm{~K}^{-1}$ & 385 \\
\hline$\lambda_{m}$ & $\mathrm{~J} \mathrm{~kg}^{-1}$ & $2.05 \times 10^{5}$ \\
\hline$\lambda_{v}$ & $\mathrm{~J} \mathrm{~kg}^{-1}$ & $4.74 \times 10^{6}$ \\
\hline$T_{m}$ & K & $1357.6-2.55 \times 10^{6} \mathrm{~d}_{\mathrm{p}}^{-1}$ \\
\hline$T_{v}$ & K & 2385 \\
\hline$\varepsilon$ sol. & $\operatorname{adm}$ & 0.6 \\
\hline$\varepsilon$ liq. & $\mathrm{adm}$ & 0.3 \\
\hline$k_{p}$ & $\mathrm{~W} \mathrm{~m}{ }^{-1} \mathrm{~K}^{-1}$ & 320 \\
\hline$M$ & $\mathrm{~g} \mathrm{~mol}^{-1}$ & 63.546 \\
\hline$R_{0}$ & $\mathrm{~nm}$ & 0.135 \\
\hline$\gamma$ & $\mathrm{N} \mathrm{m}^{-1}$ & $1.257-2 \times 10^{-4}(\mathrm{~T}-1356)$ \\
\hline$p_{\text {sat }}$ & $\mathrm{Pa}$ & $10^{\wedge}\left(10.855-16415 \mathrm{~T}^{-1}\right)$ \\
\hline
\end{tabular}

\subsection{Computational domain and boundary conditions}

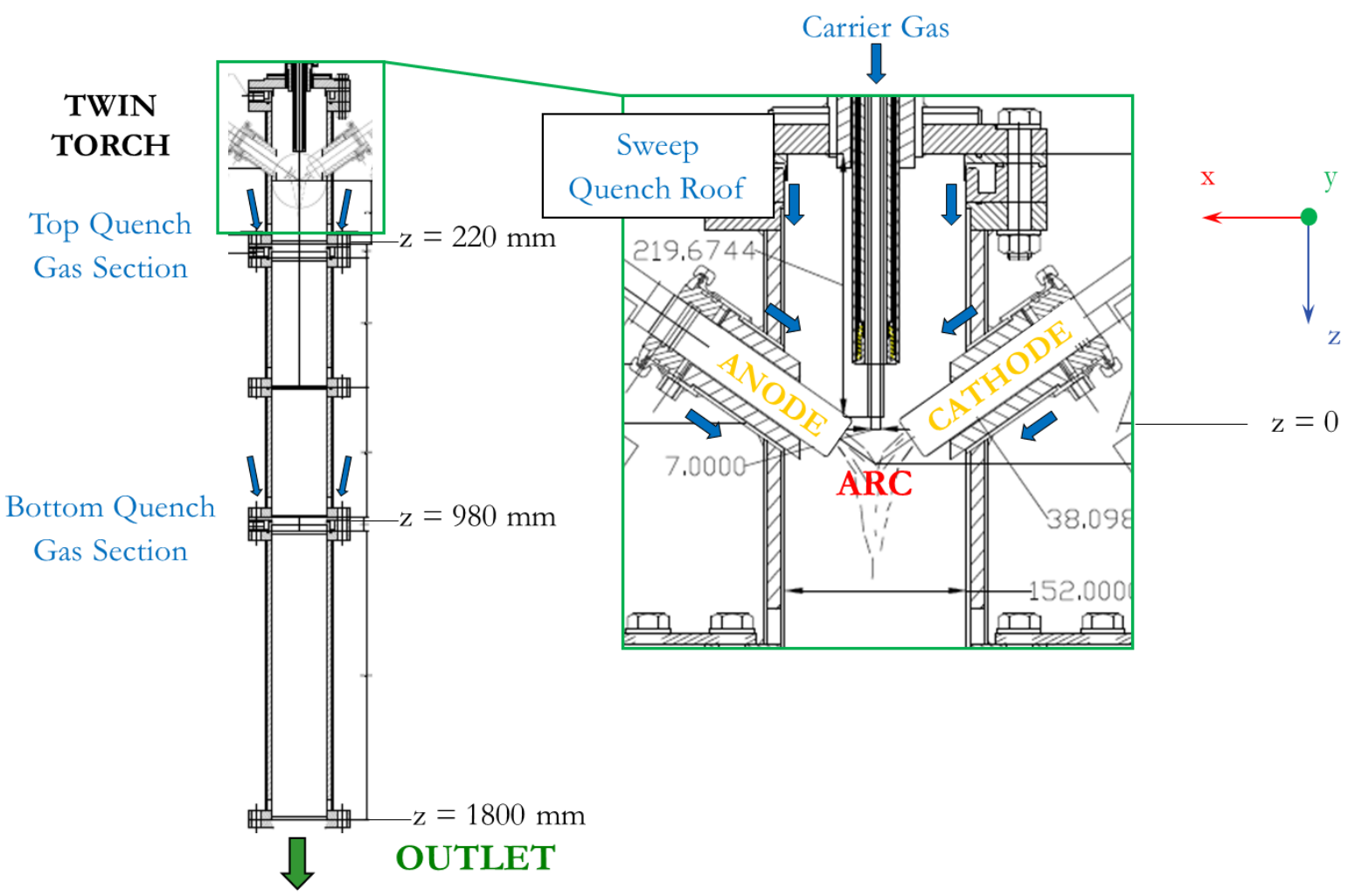

Figure 1 Schematic of the twin torch reactor geometry 
The twin torch reactor geometry is reported in Figure 1. The synthesis process occurs inside a reaction chamber, with precursors fed vertically along its axis with a carrier gas. The anode is a water-cooled copper electrode, while the cathode is a graphite electrode. The precursors are vaporized by interaction with the plasma arc and nanoparticles are synthetized in the reaction chamber by interaction with a quenching gas flow. An additional sweep gas flow is fed from the top of the reaction chamber to shield its walls from the plasma. There are two sections for the injection of the quench gas in the reaction chamber. The quench gas is injected almost parallel to the axis of the reaction chamber. In a twin torch system the strong local cooling of the plasma near the region where the material is injected and evaporated due to radiative power losses can affect the behaviour of the arc. A computational mesh of 3.8 million of polyhedral elements has been used and it is represented in Figure 2 .

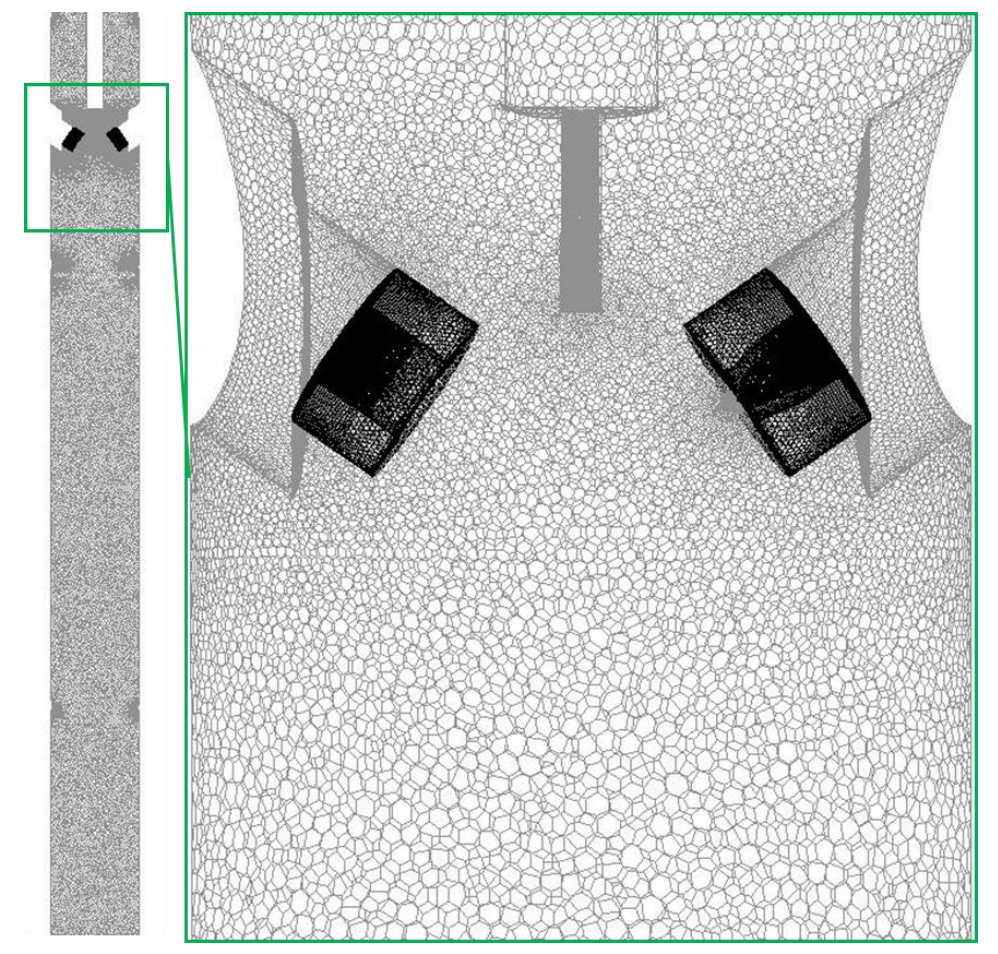

Figure 2 Complete computational mesh of the reaction chamber (left) and detail of the mesh in the inter-electrode and plasma discharge region (right).

Electrodes' interfaces are considered using a simplified approach, imposing a current density distribution on the cathode surface and a zero-voltage potential on the anode [8]. Temperatures on the surfaces of the anode and the cathode are assumed to be respectively 2000 and $3000 \mathrm{~K}$.

A no-slip boundary condition is applied on all the internal walls; boundary conditions for turbulence equations at the torch inlet are set according to Chen et al. [38]. A temperature of $300 \mathrm{~K}$ is fixed at the internal walls of the reaction chambers, corresponding to a water-cooled system. The operating pressure is set to $100 \mathrm{kPa}$.

\section{Results and discussion}


Results of plasma temperature distribution, vectors of velocity, evaporation efficiency, mean diameter and yield will be presented in this section, for two levels of operating current and precursors feed rates between 5 and $24 \mathrm{~kg} /$ day. Also nodal model results will be compared to method of moments one. This investigation is aimed to assess the industrial sustainability of a twin torch plasma system for the synthesis of $\mathrm{Cu}$ nanoparticles.

With an operative current of $1200 \mathrm{~A}$ and a precursor feed rate of $0.25 \mathrm{~kg} / \mathrm{h}$, by neglecting in the model the effect of radiative losses from $\mathrm{Cu}$, the gas temperature is higher than $6000 \mathrm{~K}$ up to several centimetres downstream the attachment of the two arc columns, as shown in the top part of Figure 3. The heat exchange with the precursors is almost negligible due to the low mass flow rate of precursors, and the evaporation efficiency is $100 \%$. As it is shown in the bottom part of Figure 3, the temperature drops down abruptly by considering $\mathrm{Cu}$ vapor properties. Still, the evaporation efficiency is almost complete (97\%), as most of the $\mathrm{Cu}$ particles cross the electric arc region, where they can reach easily their boiling temperature $(2835 \mathrm{~K})$, as shown in Figure 4. 

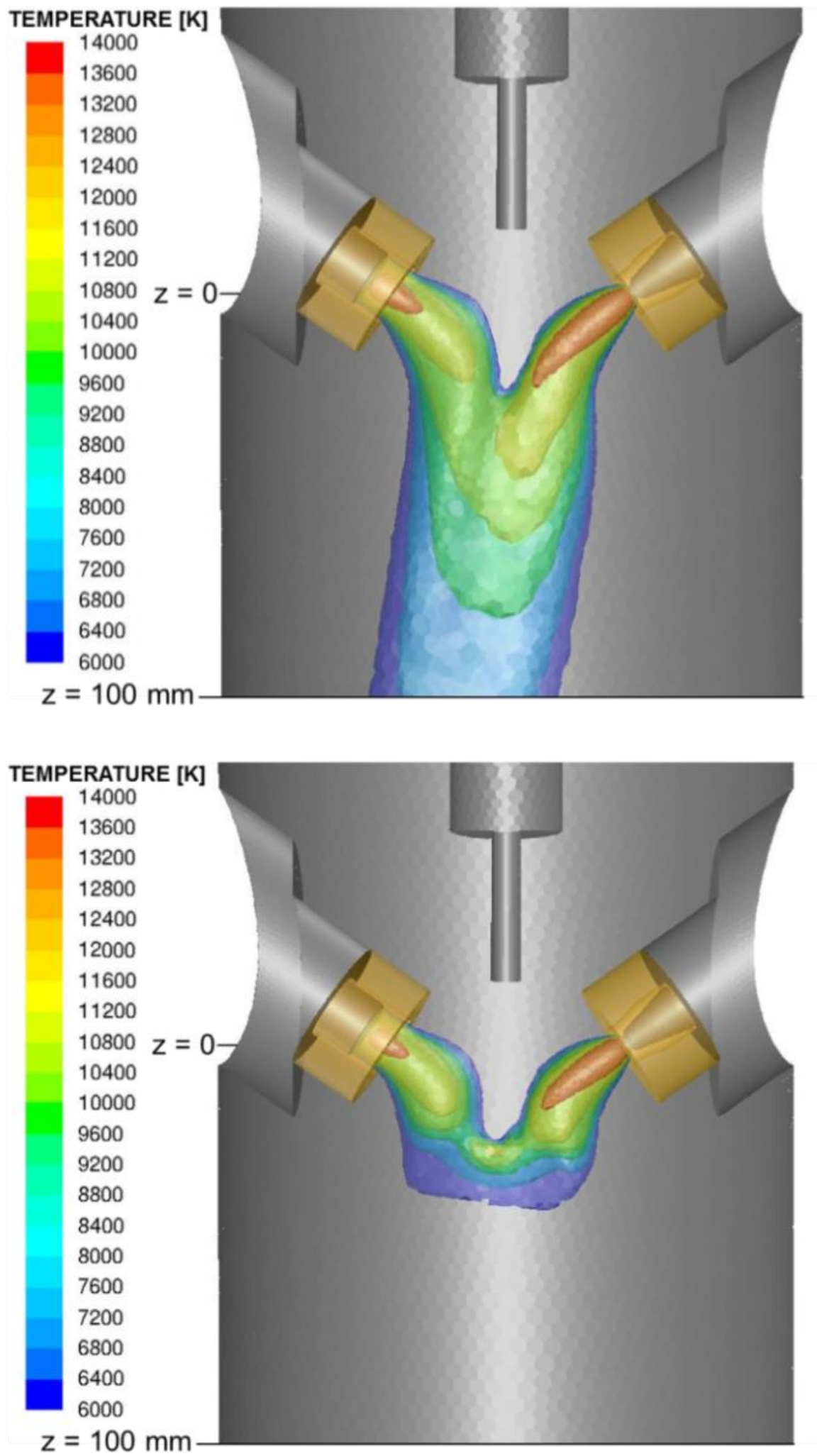

Figure 3 Temperature isosurfaces for the case at $1200 \mathrm{~A}$ and a precursor feed rate of $0.25 \mathrm{~kg} / \mathrm{h}$, calculated neglecting the effect of $\mathrm{Cu}$ vapour properties (top) and considering them (bottom). 


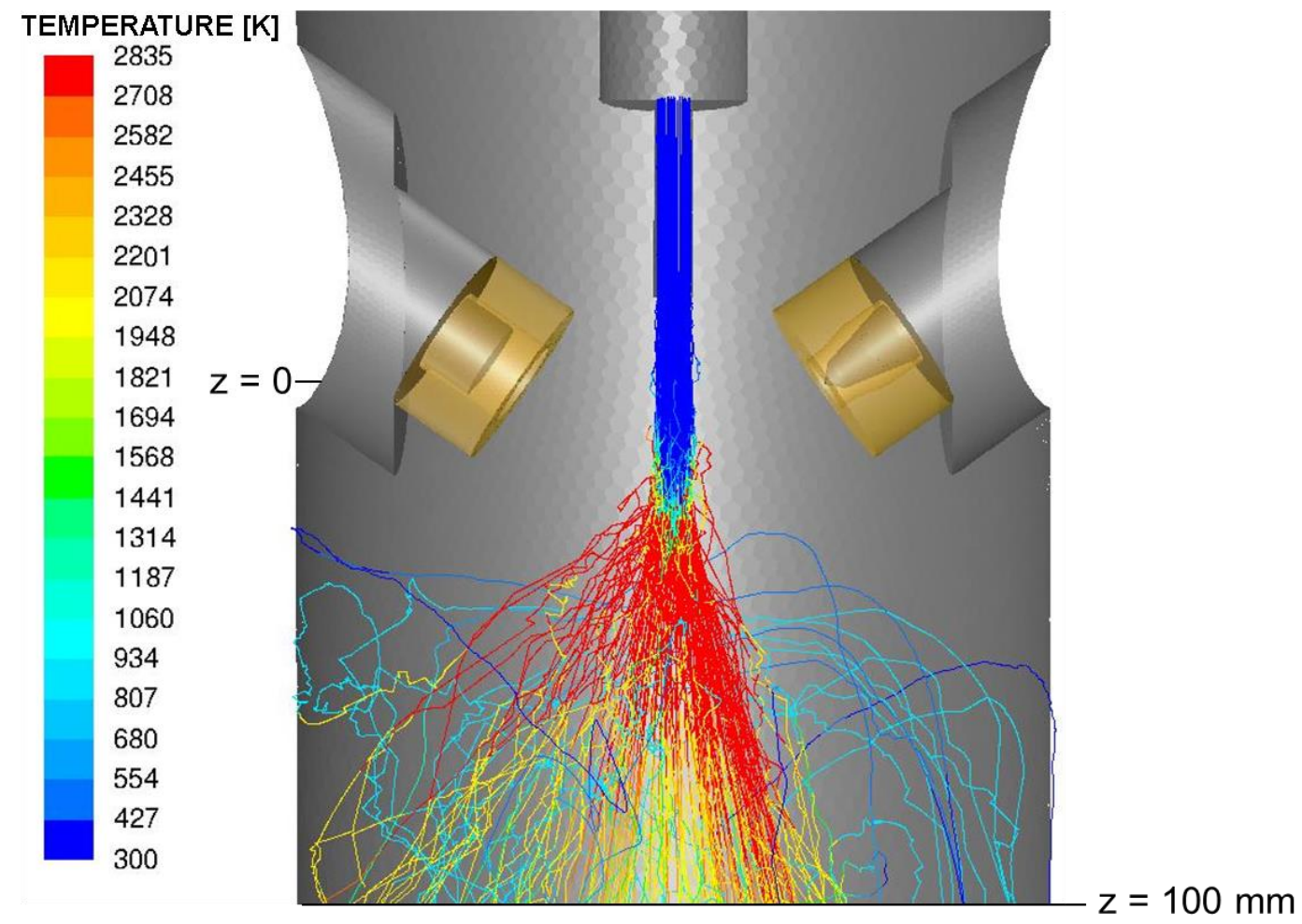

Figure 4 Precursors pathlines and thermal history for the case at $1200 \mathrm{~A}$ and a precursor feed rate of $0.25 \mathrm{~kg} / \mathrm{h}$

In Figure 5 velocity field vectors are reported for the reaction chamber region. The effect of the complex interaction between the two plasma columns and the quenching injection zone is highlighted: simulations results show that the twin torch system is particularly difficult to set in terms of operating conditions that would favour the synthesis of nanoparticles; to properly quench the high temperature plasma outflow is a challenging task. For example, if the operative current is set to $1200 \mathrm{~A}$ and the precursor feed rate at $0.25 \mathrm{~kg} / \mathrm{h}$, even with $1000 \mathrm{slpm}$ of quench gas fed through several injections at different axial positions in the reaction chamber, the effluent temperature is so high that most of the produced $\mathrm{Cu}$ vapours are yet not converted to nanoparticles; the too small amount of them that has been synthetized shows a mean diameter of $14 \mathrm{~nm}$ (Table 2). The process yield is defined as the ratio between the total nanoparticle throughput and the precursor feed rate. Nanoparticles are synthetized where the quench gas cools down the hot gas coming from the electrode region, as shown in Figure 6, with a yield of $10 \%$ (Table 2). 


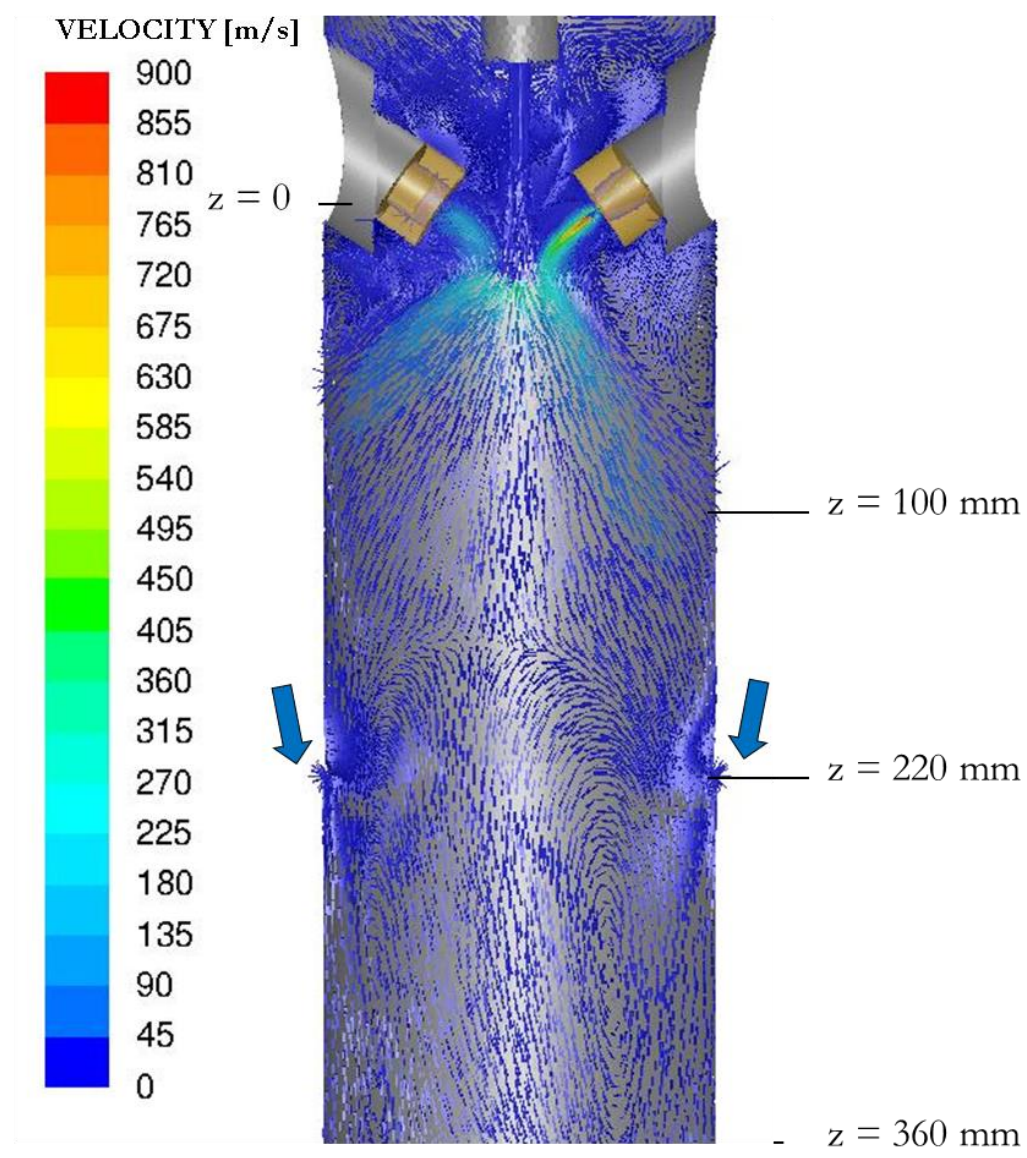

Figure 5 Vector velocity fields for the case at $1200 \mathrm{~A}$ and a precursor feed rate of $0.25 \mathrm{~kg} / \mathrm{h}$, considering the radiative losses of $\mathrm{Cu}$ vapour. The blue arrows represent the quench gas injection section.

Table 2. Summary of the performances of the synthesis process at 1200 and 520 A of operating current, with a precursor feed rate of $0.25 \mathrm{~kg} / \mathrm{h}$ and $1000 \mathrm{slpm}$ of quench gas. Mean diameter and yield of the synthetized nanoparticles obtained with method of moments.

\begin{tabular}{cccc}
\hline $\begin{array}{c}\text { Current } \\
(\mathrm{A})\end{array}$ & $\begin{array}{c}\text { Evaporation } \\
\text { efficiency }(\%)\end{array}$ & $\begin{array}{c}\text { Yield } \\
(\%)\end{array}$ & $\begin{array}{c}\overline{\boldsymbol{d}}_{\boldsymbol{P}} \text { at outlet } \\
(\mathrm{nm})\end{array}$ \\
\hline 1200 & $97 \%$ & $10 \%$ & 14 \\
\hline 520 & $68 \%$ & $6 \%$ & 22 \\
\hline
\end{tabular}




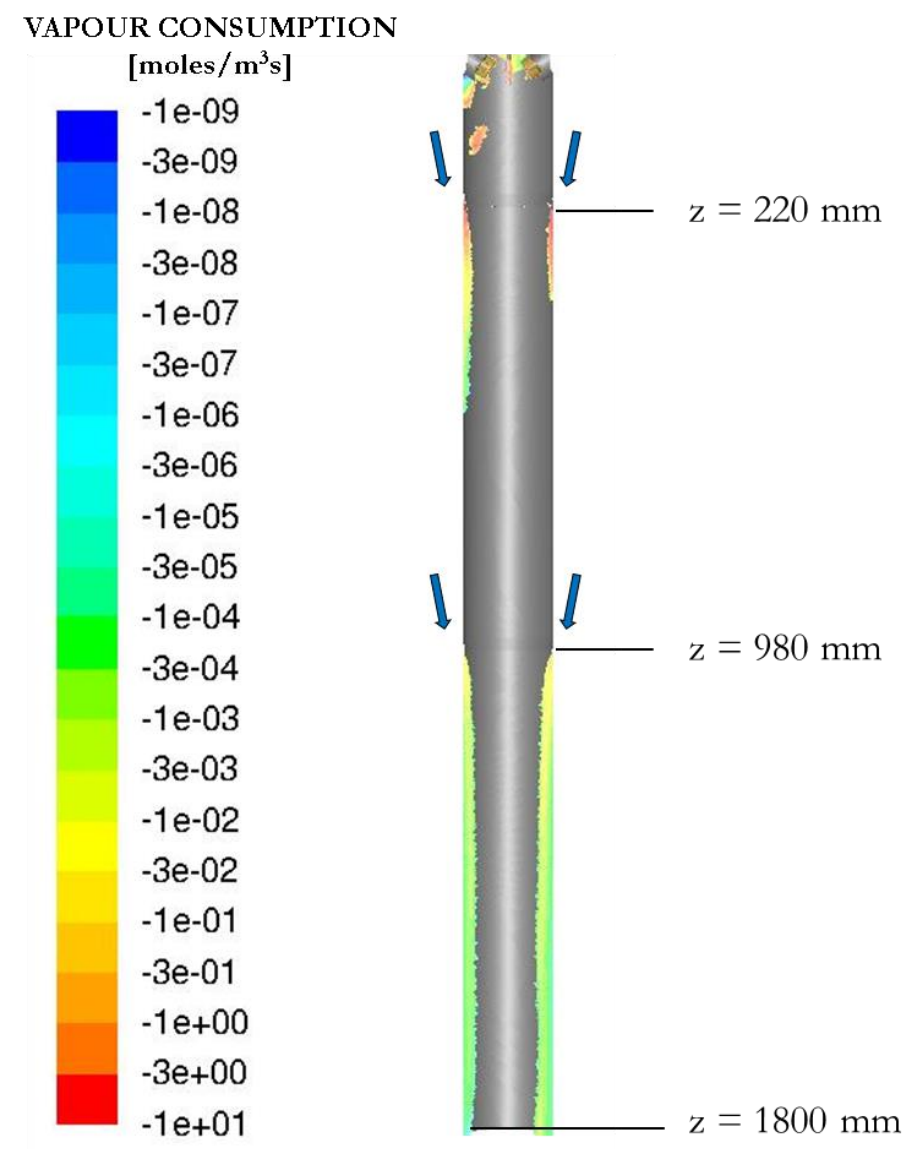

Figure 6 Vapour consumption for the case at $1200 \mathrm{~A}$ and a precursor feed rate of $0.25 \mathrm{~kg} / \mathrm{h}$, considering the radiative losses of $\mathrm{Cu}$ vapour. The blue arrows represent the quench gas injection sections.

At 520 A of operating current (Figure 7) the evaporation efficiency is close to $70 \%$ up to $24 \mathrm{~kg} / \mathrm{day}$ of precursor feed rate (

Figure 8). The experimental evaporation rate at $520 \mathrm{~A}$ was estimated by weighting the material collected in the reaction chamber and chamber walls. The total amount of collected $\mathrm{Cu}$ was $2.2 \mathrm{~kg}$. The amount of precursor injected in the system was $6.7 \mathrm{~kg}$ with a feed rate of $9.1 \mathrm{~kg} /$ day. Thus, $4.5 \mathrm{~kg}$ of precursor were evaporated corresponding to an evaporation efficiency of $67.16 \%$. This value is in good agreement with the output from simulation $(66,5 \%)$ for the same operating condition. 


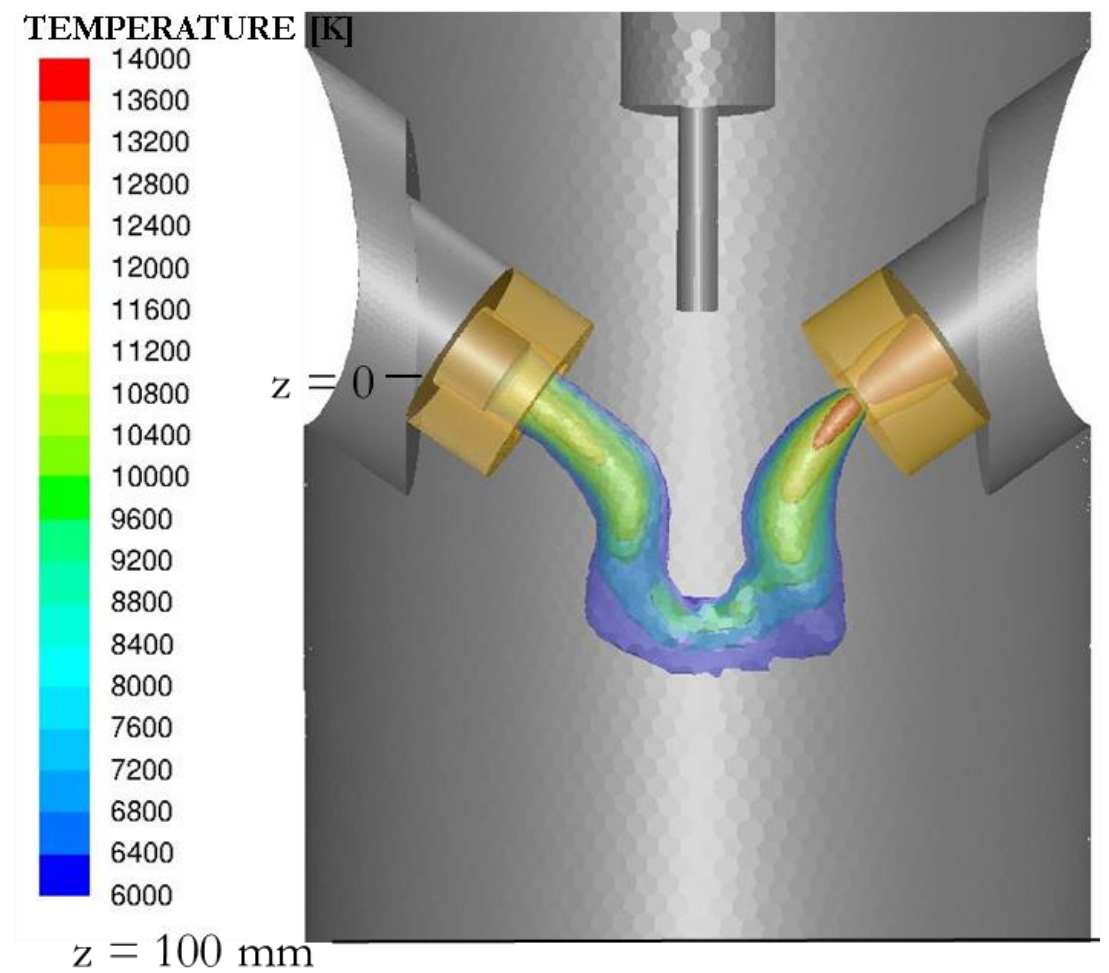

Figure 7 Temperature isosurfaces for the case at $520 \mathrm{~A}$ and a precursor feed rate of $0.25 \mathrm{~kg} / \mathrm{h}$

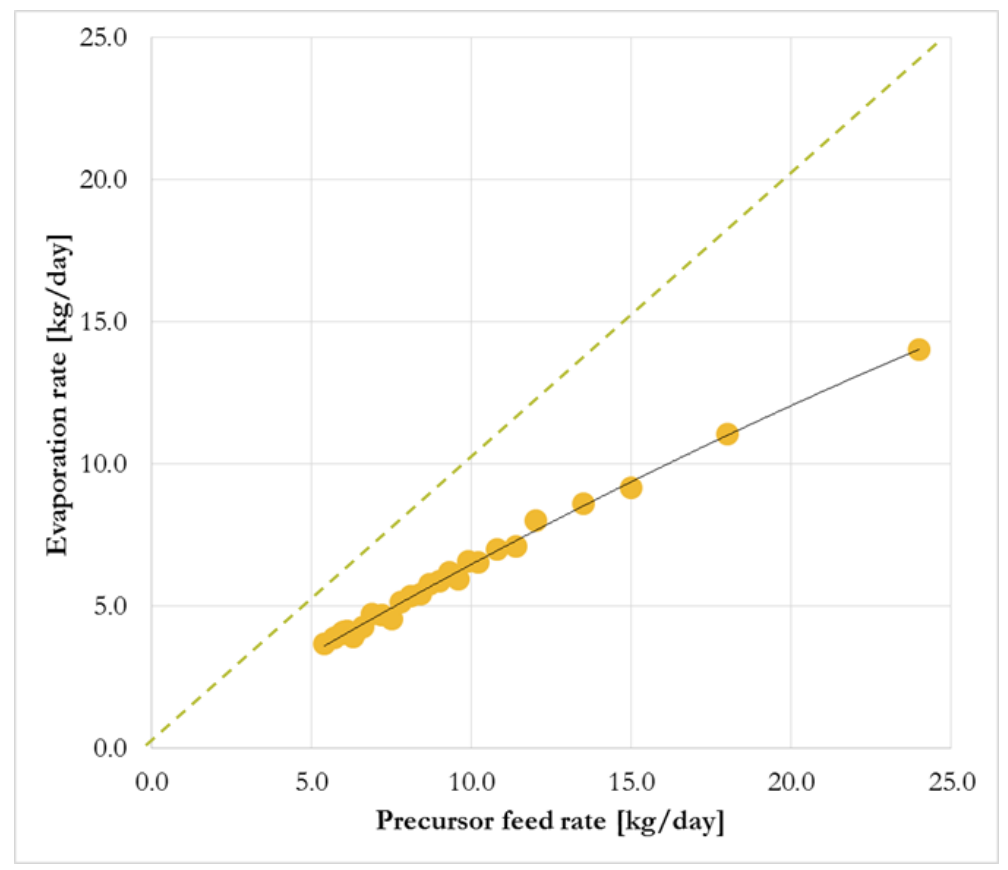

Figure 8 Evaporation efficiency at $520 \mathrm{~A}$

Results of the $\mathrm{Cu}$ nanoparticles distribution obtained using the method of moments are shown in Figure 9. Nanoparticles are lost in the chamber by wall deposition. With a complete downwards flow, growth 
mechanisms like condensation and coagulation should increase mean particle size along the reaction chamber with a unidirectional downwards flow. Vortices instead bring back upwards nanoparticles, increasing their size.

\section{Errore. L'origine riferimento non è stata trovata.}
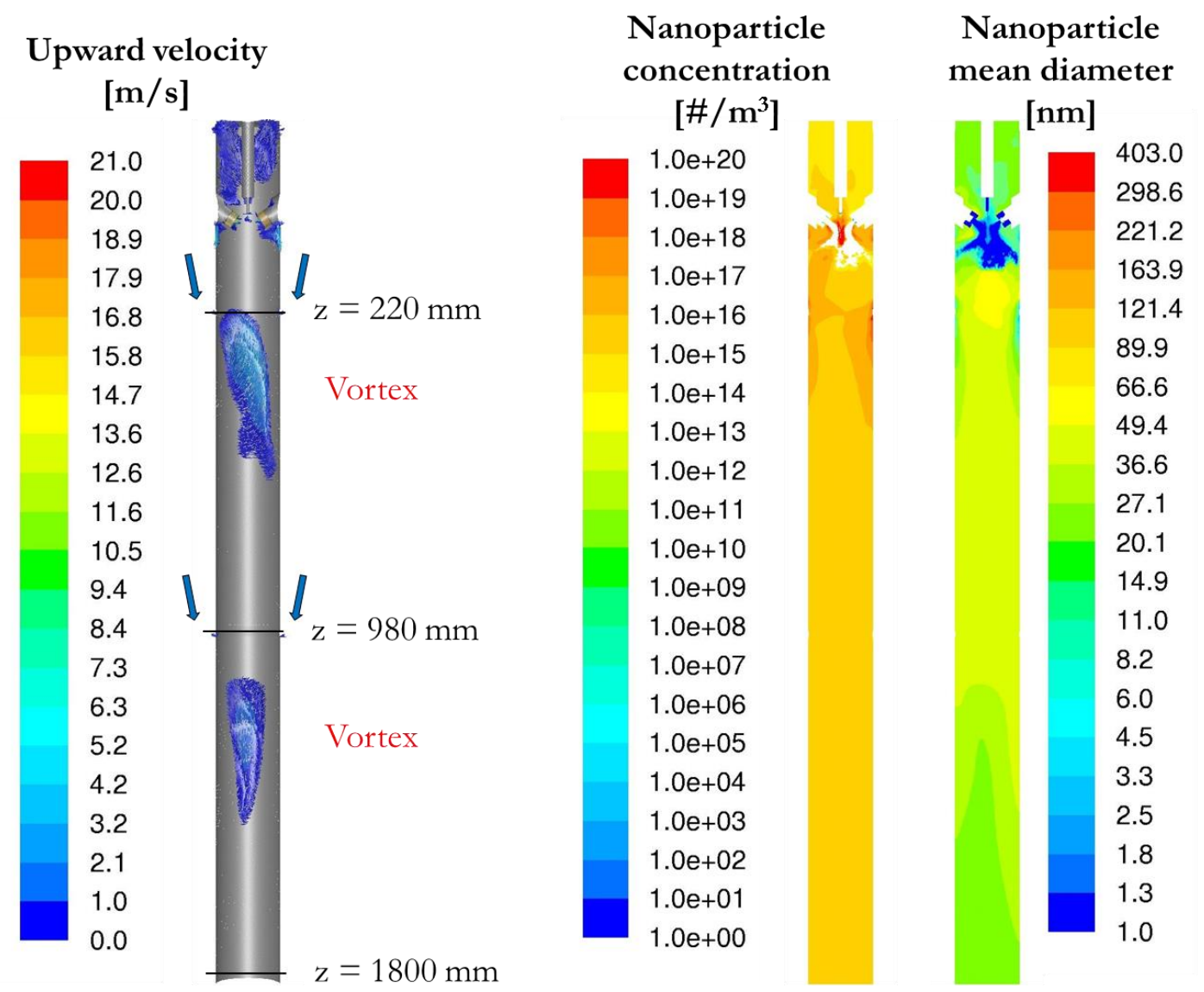

Figure 9 Nanoparticles concentration and mean diameter in the reaction chamber with the method of moments, on the right, for the case at $520 \mathrm{~A}$ and a precursor feed rate of $1 \mathrm{~kg} / \mathrm{h}$. On the left, vectors of upwards velocity, showing the presence of vortices in the chamber.

Nodal model results for the same operating condition are shown in Figure 10, where nanoparticles seem to concentrate in the region above the top vortex. The mean diameter distribution of the nanoparticles is much different with respect of the one obtainable through the method of moments, even though they have similar values ( $25 \mathrm{~nm}$ vs $22 \mathrm{~nm}$ ) characterize the outlet region.

The smallest nanoparticles $\left(\mathrm{V}_{0}\right)$ are mainly nucleated in the region above the top vortex. The particles which avoid deposition on the walls of the reaction chamber grow mainly in an intermediate dimensional range, while just a few "large" particles (diameter higher than $100 \mathrm{~nm}$ ) can be found at the outlet. In terms of results the two models have comparable values for the mean particle size at the outlet. The nodal model predicts a lower yield than the method of moments. Therefore, experimental results (not shown in this paper) on yield suggests that, at least for this operating condition, the method of moments produces a more reliable output. Considering that the nodal model didn't show any bimodal distribution and it has a quite intense computational load for a $3 \mathrm{~d}$ geometry, it is advisable to investigate the optimum operating conditions by the method of moments, followed by a verification by the nodal model of the expected PSD just for a few selected operating conditions. 

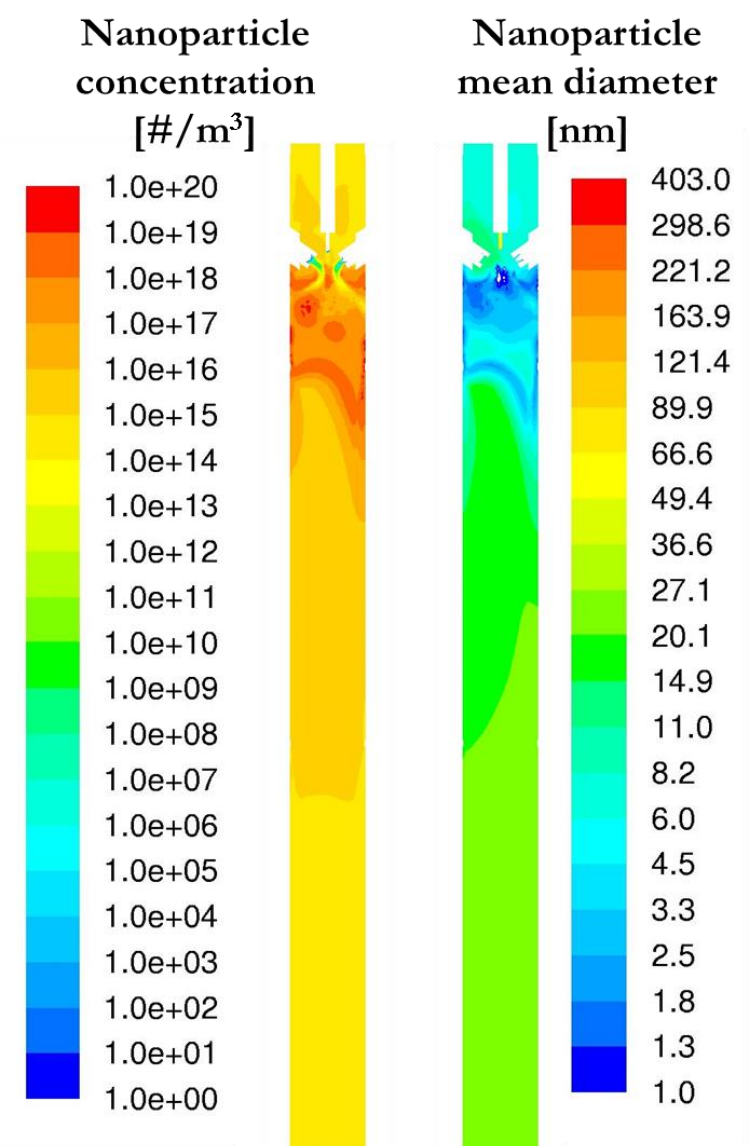
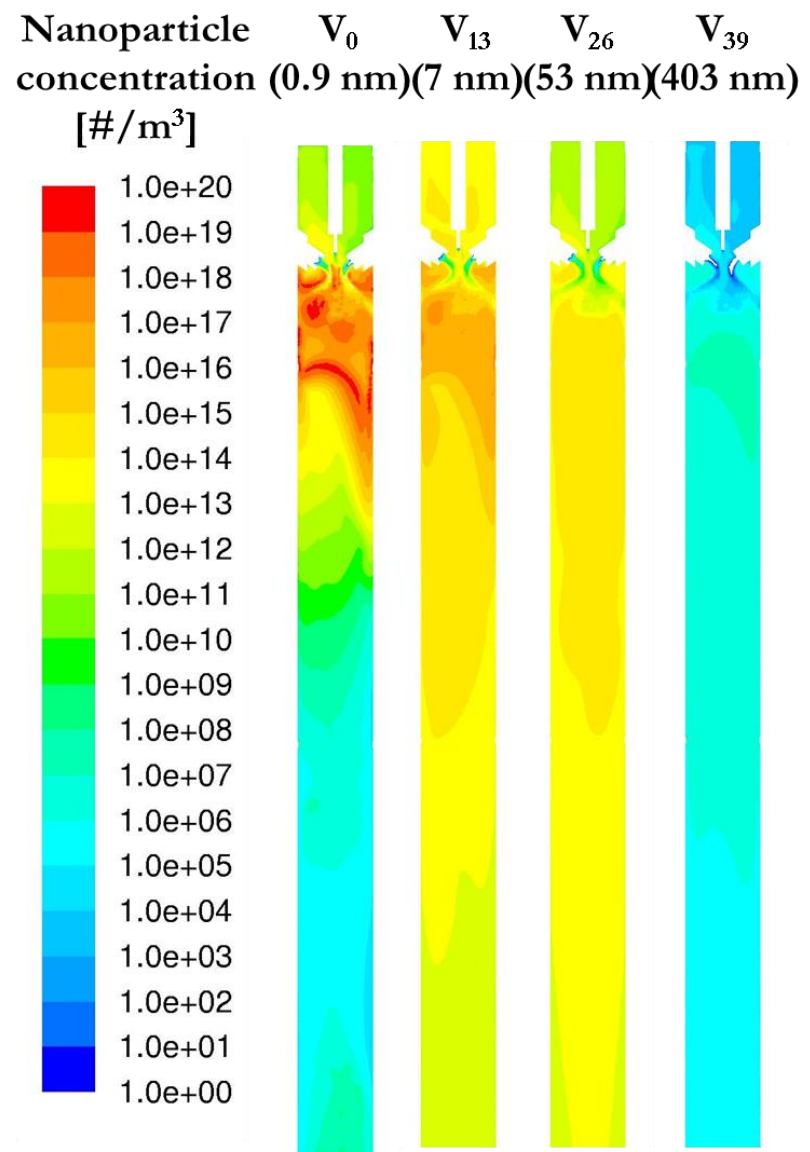

Figure 10 Nanoparticles concentration and mean diameter in the reaction chamber with the nodal method, on the left, for the case at $520 \mathrm{~A}$ and a precursor feed rate of $1 \mathrm{~kg} / \mathrm{h}$. On the right, nanoparticles concentrations for 4 node volumes of different sizes (respectively 0.9, 7, 53 and $403 \mathrm{~nm}$ ).

\section{Conclusions}

This work has been performed in the frame of the Horizon 2020 INSPIRED project for the scale up of $\mathrm{Cu}$ nanoparticles synthesis to appropriate industrial scale quantities (more than $20 \mathrm{~kg} /$ day of throughput). To assess the feasibility of this task and to seek an optimum route, a 3D thermo-fluid-dynamic model was employed to simulate the $\mathrm{Cu}$ nanoparticle synthesis process by a DC twin torch thermal plasma system. The developed model considers $\mathrm{Cu}$ vapour thermodynamic and transport properties.

The effect of different precursor flow rates, operative current and quench gas flow rates on the synthetized nanoparticles mean diameter and yield have been investigated. The adopted simulative model can describe plasma thermo-fluid dynamics, electromagnetic fields, precursor trajectories and thermal history and nanoparticle nucleation and growth. $\mathrm{Cu}$ vapour thermodynamic and transport properties have also been considered in the model. While evaporation efficiency is considerably high even at precursor feed rates up to $25 \mathrm{~kg} / \mathrm{day}$, the presence of vortices inside the chambers causes a significative loss of nanoparticles to the reactor walls, with a detrimental effect to the yield, which is almost an order of 
magnitude lower than the one obtainable by an RF-ITP system (50-70\%) [18]. In the frame of designoriented modelling, the developed models would serve as a useful tool to make the synthesis process

more industrially sustainable, also by optimizing reaction chambers to minimize this loss effect and to improve sensibly the yield. The use of a quenching gas can generate vortices which can quite negatively affect the yield. The optimization of this process is not trivial: it depends on the material to be synthetized and can be investigated by consistently changing the geometry of the reaction chamber, as well as quench gas injection sections, if technically and financially feasible; otherwise optimization can still be investigated operating only on the values of the different gas inputs involved in this complex system.

\section{Acknowledgements}

Financial support from the European Union within the Horizon 2020 research and innovation programme, under grant agreement n. 646155 (INSPIRED project http://www.nano-inspired.eu/), is gratefully acknowledged.

This is a post-peer-review, pre-copyedit version of an article published in Journal of Physics D: Applied Physics. IOP Publishing Ltd is not responsible for any errors or omissions in this version of the manuscript or any version derived from it.

The final authenticated version is available online at: https://dx.doi.org/10.1088/1361-6463/ab3607

This Accepted Manuscript is available for reuse under a CC BY-NC-ND 3.0 licence after the 12 month embargo period provided that all the terms of the licence are adhered to.

\section{References:}

[1] Shigeta M, Murphy A B 2011 J. Phys. D: Appl. Phys. 44174025

[2] Tanaka Y 2018 Handbook of Thermal Science and Engineering (New York:Springer) 27912828

[3] Kim K S, Kim, T H 2019 J. Appl. Phys. 125070901

[4] Shigeta M, Nishiyama H 2005 J. Heat Transfer 127 1223-1231

[5] Murphy A B, Boulos M I, Colombo V, Fauchais P, Ghedini E, Gleizes A, Mostaghimi J, Proulx P, Schram D C 2008 High Temp. Mater. Process. 12 255-336

[6] Colombo V, Ghedini E, Gherardi M, Sanibondi P, Shigeta M 2012 Plasma Sci. Technol 21 025001

[7] Trelles J P 2013 J. Phys. D: Appl. Phys. 46255201

[8] Shigeta M 2016 J. Phys. D: Appl. Phys. 49493001

[9] Bogaerts A, Aghaei M 2017 J. Anal. Atom. Spectrom. 32 233-261

[10] Shigeta M 2019 IEEJ T. Electr. Electr. 14 16-28

[11] Colombo V, Ghedini E, Gherardi M, Sanibondi P 2013 Plasma Sources Sci. Technol. 22 035010

[12] Boulos M I 2016 Plasma Chem. Plasma Process. 36 3-28

[13] Bianconi S, Boselli M, Gherardi M, Colombo V 2017 Plasma Chem. Plasma Process. 37717 
[14] Bianconi S, Boselli M, Gherardi M, Colombo V 2017 J. Phys. D. Appl. Phys. 50165204

[15] Shigeta M and Watanabe T 2008 J. Appl. Phys. 103074903

[16] Shigeta M, Watanabe T 2009 J. Therm. Spray Technol. 181022

[17] Mendoza-Gonzalez N Y, Goortani B M, Proulx P 2007 Material Science and Engineering C 27 1265-1268

[18] Goortani B M, Mendoza-Gonzalez N Y, Proulx P 2006 Int. J. Chem. Reactor Eng. 4 A33

[19] Colombo V, Ghedini E, Gherardi M, Sanibondi P 2012 Plasma Sci. Technol 21055007

[20] Goortani B M, Proulx P, Xue S, Mendoza-Gonzalez N Y 2007 Powder Technol. 175 22-32

[21] Heberlein J, Murphy A B 2008 J. Phys. D: Appl. Phys. 41053001

[22] Colombo V, Concetti A, Ghedini E 2008 IEEE Trans. Plasma Sci. 361038

[23] Tang K M, Yan J D, Chapman C, Fang M T C 2010 J. Phys. D: Appl. Phys. 43345201

[24] Colombo V, Ghedini E, Boselli M, Sanibondi P, Concetti A et al. 2011 J. Phys. D: Appl. Phys. 44194005

[25] Guo H, Wu G Q, Li H P, Bao C Y 2015 Plasma Chem. Plasma Process. 35 75-89

[26] ANSYS 2013 ANSYS FLUENT 15.0 Theory Guide (Canonburg, PA: Ansys)

[27] Cressault Y, Murphy A B, Teulet Ph, Gleizes A, Schnick M 2013 J. Phys. D. Appl. Phys. 46 415207

[28] Cressault Y, Gleizes A 2013 J. Phys. D: Appl. Phys. 46415206

[29] Gleizes A, Cressault Y, Teulet Ph 2010 Plasma Sci. Technol. 19055013

[30] Colombo V, Ghedini E, Sanibondi P 2010 Plasma Sci. Technol 19065024

[31] Gelbard F, Tambour Y, Seifield J H 1980 J. Colloid Interface Sci. 76 541-556

[32] Girshick S K, Chiu P C, McMurry P H 1990 Aerosol Sci. Technol. 13 465-477

[33] Proulx P, Mostaghimi J, Boulos M 1987 Plasma Chem. Plasma Process. 7 29-52

[34] Seinfeld J H, Pandis S N 1998 Atmospheric chemistry and physics, from air pollution to climate change $1^{\text {st }}$ edn (NewYork: Wiley)

[35] Smoluchowski M 1917 Z. Phys. Chem. 92 129-168

[36] Bourasseau E, Homman A, Durand O, Ghoufi A, Malfreyt P 2013 Eur. J Phys. B 86251

[37] Lide D R 2003 Handbook of Chemistry and Physics, 84 ${ }^{\text {th }}$ Ed. (CRC Press)

[38] Chen K Boulos M I 1994 J. Phys. D: Appl. Phys. 27946 